\title{
Ensinar e avaliar cientificamente a matemática nos anos iniciais: Lourenço Filho e a Revista Escola Nova
}

\author{
Wagner Rodrigues Valente \\ Professor, UNIFESP \\ wagner.valente@unifesp.br
}

\section{Nara Vilma Lima Pinheiro}

Doutoranda, UNIFESP

naravilmal@gmail.com

\begin{abstract}
Resumo
Na década de 1930, Lourenço Filho era diretor da instrução pública paulista. Nessa época, editou, como estratégia de convencimento dos professores para aderirem à chamada pedagogia científica, um número especial da revista Escola Nova. O objetivo deste artigo é analisar como a publicação dos estudos contidos na revista permite-nos apreender as representações científicas para verificação de habilidades aritméticas na escola primária. Faz-se uso de ferramental teórico-metodológico vindo da História Cultural no estudo dos dados empíricos do trabalho. Obtém-se como resultado mais amplo o desvelar do modo como Lourenço Filho articulou os textos escolhidos para a revista conjugando propostas muito diferentes, tratando-as como complementares. Como resultado específico da investigação verifica-se que a avaliação das habilidades aritméticas por meio dos testes, àquele tempo, estava muito mais relacionada à promoção da eficiência do ensino, e menos próxima do que viria ocorrer décadas mais tarde com os estudos sobre aprendizagem matemática.
\end{abstract}

Palavras-chave: História da Educação Matemática. Aritmética. Curso Primário de Aritmética. Lourenço Filho. Revista Escola Nova.

\section{Teach and evaluate scientifically math in primary school: Lourenço Filho and the Escola Nova Journal}

\begin{abstract}
In the 1930s, Lourenço Filho was director of the São Paulo public education. At that time, edited, as teachers of convincing strategy to join the call scientific pedagogy, a special issue of the Nova Escola journal. The purpose of this article is to reveal the publication of the studies contained in the journal allows us to grasp the scientific representations to check arithmetic skills in elementary school. We make use of theoretical and methodological tools from the Cultural History in the analysis of empirical data from the study. We got wider as a result the broader reveal how Lourenço Filho articulated the texts chosen for the journal combining very different proposals treating them as complementary. As a specific result of the study it appears that the evaluation of arithmetic skills through tests, at that time, was much more related to the promotion of teaching efficiency, and less close to what would occur later decades with the studies on mathematics learning.
\end{abstract}


Keywords: History of Mathematics Education. Arithmetics. Primary School, Lourenço Filho. Escola Nova Journal.

\section{Introdução}

É senso comum pedagógico e orientador de práticas avaliativas utilizadas por professores, já de há muito tempo, a formulação de testes. De caráter um tanto demorado para a sua confecção, revela-se rápido no inventário de respostas e atribuição de notas àqueles que a eles se submetem. Também faz parte do senso comum pedagógico organizar testes sob a dosagem de "fáceis, médios e difíceis" para os itens a serem avaliados. Inclui-se, também, no dia a dia dos ensinos, a organização de classes consideradas "fracas, fortes" etc. mesmo que isso, muitas vezes, não fique explícito para a população escolar. Esse sentido de graduação, de escalonamento da avaliação e de seus resultados têm uma história. E as contribuições da matemática e da estatística, em particular, foram decisivas para cunhar e trazer até os dias de hoje essas representações com as quais os professores lidam no seu ofício docente. Como foram construídas essas representações que tão fortemente têm presença no cotidiano escolar atual? Este texto busca responder a esta questão a partir das ações do educador Lourenço Filho.

\section{Lourenço Filho e os testes: "rumo a uma verdadeira pedagogia experimental"}

Na década de 1920, a pedagogia buscava na psicologia de base experimental subsídios considerados científicos para elucidação da realidade escolar. Tratava-se de transformar a mentalidade e a prática pedagógica do professorado, com vistas a fornecer a desejada base científica à organização escolar. Pensava-se não ser mais possível realizar o ofício docente sem que se fizesse uso dos avanços e conquistas da psicologia e seus métodos, aplicados à educação. E, dentre o aparato vindo da psicologia, situavam-se os testes.

No âmbito paulista, Lourenço Filho foi um dos maiores divulgadores do uso dos testes na escola primária. Sob o governo de Getúlio Vargas, na década de 1930, ele assumiu a Diretoria da Instrução Pública paulista e iniciou a reforma do ensino que adotava os princípios da chamada Escola Nova. Além disso, ele reorganizou o periódico pedagógico publicado por essa diretoria, o qual deixou de denominar-se Educação, passando a designar-se Escola Nova. A revista tinha por objetivo incentivar o "estudo científico da criança, para o conhecimento da nova psicologia e de suas surpreendentes aplicações" (LOURENÇO FILHO, 1930, p. 4). Neste sentido, as técnicas do emprego dos testes tiveram papel marcante (MELLO, 2007). 
Para além do estudo científico da criança, a estratégia ${ }^{1}$ de Lourenço Filho na publicação dessa coleção era dar subsídios teóricos visando mudanças na cultura pedagógica do professorado. Tais mudanças se dariam quando os problemas pedagógicos deixassem de ser tratados de modo empírico para serem ajustados cientificamente, segundo a ótica desse educador. Nessa perspectiva, o uso dos testes possibilitaria "a organização de normas de uma verdadeira pedagogia experimental, cujas conquistas são (seriam) de alcance inestimável para a economia da própria administração" (LOURENÇO FILHO,1930, p. 17).

Nas escolas, o principal objetivo dos testes seria "avaliar até que ponto chegaram os alunos na assimilação dos programas" (LOURENÇO FILHO, 1931, p. 255) e classificar tanto a inteligência quanto a aptidão dos discentes. Mas não se tratava de atribuir a qualquer prova o nome de teste: era necessário que o professor escolhesse aqueles que foram estandardizados por profissionais especializados. Assim, na origem, os testes têm caráter diferente daqueles que hoje se aplicam sob esse nome, que obrigatoriamente envolvem alternativas de respostas a uma dada interrogação. Eles caracterizavam itens de avaliação já padronizados, inventariados estatisticamente e colocados na forma de uma normativa de avaliação. Em suma, itens já testados...

Nesse sentido, Lourenço Filho publicou um número específico da revista Escola Nova intitulado "Iniciação aos testes" (1931). O objetivo era introduzir os professores na rota dos testes. Para compor essa edição, ele contou com o auxílio do Dr. A. Raspantini e do professor J. Damasco Penna na tradução de partes do livro La medida objectiva del trabajo escolar e da obra Introduction to the use of standard tests, respectivamente.

Neste artigo procuramos analisar, a partir das obras escolhidas como referência para publicação na referida revista, as representações ${ }^{2}$ para mensuração do rendimento do ensino de aritmética na escola primária. Para tanto, tomamos como fonte privilegiada o estudo das duas obras citadas anteriormente. À luz de Michel de Certeau (1991), consideramos que a publicação na revista integrou uma estratégia para legitimar e justificar os ideais escolanovistas apropriados por Lourenço Filho para reformar a instrução pública paulista, em termos de penetração de uma pedagogia científica, de base experimental. A partir dos testes, como tal pedagogia tratou a aritmética a ser ensinada no curso primário?

\footnotetext{
${ }^{1}$ Servimo-nos dos estudos de Michel de Certeau (2012, p. 45) que toma estratégia como "as relações de força que se torna possível a partir do momento em que um sujeito de querer e poder é isolável de um 'ambiente"”. A estratégia constitui-se como mecanismo de dominação.

${ }^{2}$ A partir de Roger Chartier (2002, p. 17), considera-se que a noção de representação diz respeito ao modo como a realidade é construída em diferentes lugares e tempos, pelos interesses de grupos que as forjam por meio de classificações, divisões e delimitações. Em nosso caso, os modos e categorias utilizadas no cotidiano escolar para avaliar.
} 


\section{Iniciação aos testes: a referência européia na revista Escola Nova}

O primeiro artigo publicado na revista Escola Nova, intitulado "Conceito da medida do trabalho escolar" é uma tradução da primeira parte do livro La medida objetiva del trabajo escolar (1924), do pedagogo e secretário do Conselho de Pedagogia de Barcelona, Alejandro Gali. Esse autor é considerado um dos percursores da renovação pedagógica e o primeiro a experimentá-la na Espanha, apoiado por autores como Thorndike, Burt, Bovet, dentre outros, que se debruçaram sobre os estudos empírico-experimentais dos fenômenos educativos.

No texto traduzido, Gali (1931, p. 267) defendia que era necessário mais do que vocação para ser um bom mestre, era preciso uma "consciência técnica", pois o conhecimento preciso do trabalho escolar permitiria "coordenar o ritmo com os progressos da técnica e com as necessidades da vida moderna". Esta consciência técnica permitiria por meio de testes e de programas elaborados experimentalmente verificar se o conteúdo que se desejava ensinar estava de acordo com a idade da criança e se os processos empregados se adaptavam à psicologia infantil. Mais do que isto: se o interesse pretendido era vital ou apenas um passatempo. Como já dito, o intento era que o professor abandonasse as observações empiristas, tendo em conta uma pedagogia não científica, pois a valorização quantitativa autorizaria o diagnóstico e ofereceria uma base segura para tratar os problemas do ensino.

Inspirado nos estudos do pedagogo americano Leonard Ayres, Gali (1931) defendia que as próprias matérias de ensino deveriam ser organizadas em forma de testes. No caso da Aritmética, o professor poderia oferecer:

[...] uma série de exercícios cientificamente ordenados e valorizados, cujo nível de execução fornece, automaticamente, a medida desejada. Em sua forma externa, estes exercícios são como as séries ordinárias de problemas escolares, porém, cada um deles tem uma significação precisa relativa a idade e ao grau (GALI 1931, p. 293-294).

O aluno teria que resolver os exercícios sem perceber que se tratava de um teste, tal como um trabalho escolar. Assim aplicados, tinha-se uma "valorização do programa escolar, que dê por si mesma a avaliação da criança sem necessidade de recorrer a medidas especiais" (GALI, 1931, p. 294).

Em vista da dificuldade de aplicar esta forma de teste, pois demandaria uma intensa preparação, Gali (1931, p. 294) propunha um processo similar ao de Ayres. Sua proposta era "converter em testes, determinados momentos do trabalho escolar, condicionado este da maneira mais formal possível". Ambas as propostas tinham por objetivo "adaptar-se à vida real, fugindo do artificialismo que o teste clássico traz consigo" (GALI, 1931, p. 294). 
O que se percebe no texto de Gali (1931) era que ao transformar o trabalho escolar o professor teria um maior envolvimento com a técnica dos testes que em muitos momentos destinava-se apenas aos especialistas ou examinadores. Está aí, ao que parece, um ponto de inflexão, de modo a fazer o professor apropriar-se de um saber considerado até então fora de seu ofício: elaborar testes. Ele também defendia que o controle externo só seria eficiente se trouxesse consigo o interesse prévio do professor pela reorganização da vida escolar. Para tanto os standards deveriam ser vistos como programa de ação, "um programa estabelecido mais racionalmente que qualquer outro, e que pode ser tomado como modelo de grande benefício em favor da educação dos povos" (GALI, 1931, p. 303).

Como se percebe a adoção da medida objetiva do trabalho escolar favoreceria uma adaptação do programa de ensino ao desenvolvimento psicológico da criança rompendo com a ideia de sistematização lógica dos conteúdos das matérias escolares. Isto nos leva a conjecturar que os testes determinariam a ordem psicológica a partir do momento que ficasse estabelecido quais conteúdos as crianças de determinada idade aprendiam/não aprendiam em virtude do seu desenvolvimento psicológico.

\section{Iniciação aos testes: a referência estadunidense na revista Escola Nova}

Na sequência à publicação do artigo de Gali seguia-se a tradução de parte da obra, Introduction to the use of standard test, escrita por Sidney L. Pressey, assistente na Universidade de Indiana no período de 1917 a 1921, em parceria com Luella Cole Pressey, sua esposa. Durante o tempo que passou nessa Universidade pesquisou crianças de baixo QI (consideradas anormais), mas logo se interessou por aquelas que possuíam habilidades superiores, resultando em 1922 na publicação do livro citado anteriormente. Em 1925, essa obra foi traduzida e adaptada ao idioma francês pelo professor René Duthil da Escola Primária Superior de Nancy - França, sob o título de Initiation à la méthode des tests. E foi essa tradução francesa a utilizada para publicação na revista Escola Nova.

A parte publicada na revista sob o título Técnica do Emprego dos Testes tinha por objetivo principal iniciar o professorado na aplicação dos testes auxiliando-o na escolha e leitura estatística dos resultados obtidos.

De início, os autores esclareceram o termo "testes" para evitar confusão com as provas tradicionais presentes no ensino. Com o surgimento dos testes graduados a palavra ganhou outro significado, diferentemente das provas escolares, as quais constavam de questões "que o professor tinha escolhido por que elas pareciam versar sobre os pontos mais importantes do assunto estudado", mas que poderiam causar divergência quando comparadas com opiniões de outros professores (PRESSEY, S.; PRESSEY, L., 1931, p. 304). Tratava-se de convencer os professores 
que ainda tinham dúvidas quanto a validade e eficácia dos testes produzidos por especialistas, pois consideravam que a observação direta de seus alunos e seu trabalho eram as formas mais seguras de se obter informações mais precisas sobre a aprendizagem. Para tal convencimento, os especialistas escolhiam os pontos principais de um determinado assunto para compor um teste após uma intensa pesquisa de experimentação para ajuste e estandardização. Para os especialistas "os melhores testes eram os baseados nos fins primordiais que um dado ensino procura atingir, e as questões são escolhidas em face desses fins” (PRESSEY, S.; PRESSEY, L., 1931, p. 306).

No ambiente escolar, os testes ajudariam a resolver os problemas escolares de ordem administrava e pedagógica. A homogeneização da classe era um desses problemas. Esperava-se com a homogeneização que a prática pedagógica obtivesse melhores resultados em relação ao rendimento dos alunos, pois os testes possibilitariam ao professor "adaptar seu ensino às aptidões de cada um dos grupos formados e as aptidões de cada um dos alunos desses grupos" (PRESSEY, S.; PRESSEY, L., 1931, p. 314). Mas conhecer apenas as aptidões dos alunos não era suficiente; seria necessário conhecer o grau de conhecimento que eles possuíam nas matérias que lhes seriam ensinadas. Para tanto, o professor deveria fazer uso dos testes de instrução. $\mathrm{Na}$ aritmética deveriam ser utilizados os testes de Courtis para verificar os conhecimentos dos alunos em cálculo, permitindo ao professor saber "em que ponto estão os alunos e de que ponto convém fazer partir o ensino". Caso esses testes revelassem que a classe ou que alguns alunos eram fracos em adição, o professor deveria identificar, mais especificamente, quais “os pontos fracos, a fim de poder dar-lhes remédio, insistindo sobre eles de forma especial" (PRESSEY, S.; PRESSEY, L., 1931, p.315). Na sequência aplicar-se-iam os testes de diagnósticos para verificar se "a fraqueza em adição se prende ao facto de os alunos não saberem fazer as memorizações” (PRESSEY, S.; PRESSEY, L., 1931, p. 315). Identificado o ponto fraco, o professor deveria dar um ensino corretivo por meio de testes especiais composto de exercícios sistemáticos.

Tanto os estudos de Gali (1931) quanto os de Pressey e Pressey (1931) sugeriam indiretamente que o professor procurasse as obras completas para aprofundarem os estudos, uma vez que em alguns momentos os tradutores faziam menção a capítulos que não foram publicados na revista. Para melhor compreender como estes intelectuais pensavam a medida objetiva da aritmética recorremos às obras originais, de modo integral.

\section{Os testes de aritmética segundo a referência estadunidense}

Estruturada em 263 páginas a obra, Introduction to the use of standard test, divide-se em quatro partes. Na primeira, explorada anteriormente, tinham-se as explicações gerais sobre a aplicação de testes na escola primária e os conhecimentos estatísticos necessários para auxiliar os profissionais 
da educação na interpretação dos resultados obtidos. A segunda destinava-se aos testes pedagógicos para verificação da aprendizagem de determinados saberes da escola primária e da escola secundária. Na terceira, faziam-se algumas considerações sobre os testes mentais de aplicação individual e outros de aplicação coletiva, ambos destinados a medir a capacidade intelectual dos alunos. Na quarta e última, há aspectos gerais relativos a organização e estandardização de testes.

Em se tratando da mensuração da habilidade aritmética, os autores consideravam que na escolha dos testes aritméticos era importante ter claro o que se desejava mensurar, caso contrário os testes seriam uma prova a mais para os alunos resolverem. Nesse sentido, foram apresentadas duas categorias de testes: os muitos gerais e os mais específicos. Os muitos gerais indicavam a capacidade de manuseio, rapidez e precisão em combinações fundamentais dos números, mas não diagnosticavam dificuldades específicas, assim não poderiam ser utilizados para informar sobre pontos fortes ou fracos.

Os testes gerais mais conhecidos eram os de Woody-Mc Call e os de Courtis, série B. O teste de Woody-Mc Call tinha por objetivo medir a eficiência nas operações aritméticas, apresentado em única folha, e constituía-se por problemas sobre as quatro operações, inteiros e frações. Já o teste de Courtis, série B, destinado ao diagnóstico de cada uma das operações, era o mais divulgado. Tratava-se de uma escala com quatro páginas, sendo cada uma delas com 24 exercícios de cada operação. Essa quantidade de exercícios foi selecionada por permitir incluir todas as combinações numéricas possíveis.

Para Pressey, S. e Pressey, L. (1922), se uma criança se saísse bem num teste geral era indicativo de que ela dominou vários elementos e obteve habilidade com o trabalho numérico, caso contrário seria preciso investigar o motivo. Se a dificuldade fosse com a adição, o motivo provável era que a criança conhecesse as combinações numéricas, mas não soubesse perfeitamente como utilizá-las. Para dar um exemplo específico, o resultado das pesquisas indicavam que, para a maioria das crianças, era mais fácil efetuar o cálculo de $6 \times 9$ do que o de $9 \times 6$, ainda que matematicamente os resultados não se alterassem.

Devido a possibilidade dos testes de diagnósticos apontarem dificuldades específicas, eles eram úteis para direcionar a prática pedagógica do professor, pois para cada tipo de dificuldade em uma operação existia um teste específico, como por exemplo, numa série de diagnósticos havia quatro testes separados para adição de números inteiros, conforme figura 1. 
Figura 1 - Testes para adição

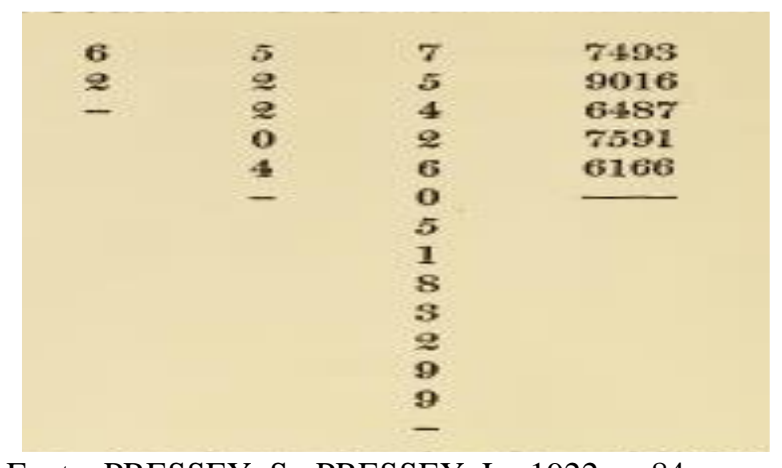

Fonte: PRESSEY, S.; PRESSEY, L., 1922, p. 84.

Os dois primeiros exemplos foram considerados mais acessíveis às crianças, enquanto os dois últimos mais difíceis, pois demandavam maior tempo e atenção para a execução. De modo geral, seria possível que uma criança executasse os dois primeiros exemplos de maneira rápida e eficiente, e fosse incapaz de trabalhar com os dois últimos exemplos (PRESSEY, S.; PRESSEY, L.,1922).

Diferentemente dos testes gerais, que indicavam apenas que uma criança era deficiente em aritmética, os testes específícos ou de diagnóticos permitiam identificar cada dificuldade, apontando pontos fortes e fracos na habilidade aritmética. Uma vez diagnosticada a dificuldade, esta deveria ser superada pela instrução e prática pedagógica adequadas. Os resultados com os testes deveriam ser utilizados como ponto de partida para uma instrução corretiva.

Além dos testes de diagnóstico Pressey, S. e Pressey, L. (1922) indicavam os testes também na resolução de problemas com a justificativa de que a habilidade nas operações fundamentais não deveria ser um fim em si mesmo, as crianças deveriam saber utilizá-las nos problemas práticos, para desenvolver o raciocínio aritmético. Os problemas selecionados para os testes deveriam ser parecidos com os estudados na escola, não poderiam conter um vocabulário e nem conhecimentos aritméticos inacessíveis às crianças. Esses testes eram necessários, pois permitiam um duplo diagnóstico: os conhecimentos das operações aritméticas e o princípio empregado na resolução. Esse duplo diagnóstico contribuiria para uma ideia mais específica das necessidades da classe. Neste caso, os testes indicados foram os de Monroe e a Escala de Buckingham.

$\mathrm{Na}$ análise do livro estadunidense percebe-se uma investida na reconstrução dos métodos de ensino a partir do uso dos testes. Esse seria o fruto de um verdadeiro 'movimento dos testes'.

\section{Os testes de aritmética e a referência europeia}

Com quase 300 páginas, o livro La medida objetiva del trabajo escolar, divide-se em duas partes. A 
primeira, destinada a reforçar a importância da aplicação dos testes para as comprovações dos problemas pedagógicos, tratada anteriormente. A segunda constituía-se por quatro seções: $1^{\text {a }}$ ) apresentava conhecimentos estatísticos necessários para lidar com os resultados da aplicação dos testes; $2^{\mathrm{a}}$ ) e $3^{\mathrm{a}}$ ) contemplavam discussões e exemplos de testes de leitura, ortografia, composição, cálculo aritmético, gramática, geometria e geografia; $4^{\mathrm{a}}$ ) tratava duma sistematização geral.

Em se tratando da aritmética, os testes estandardizados verificavam os seguintes aspectos: aquisição do mecanismo das operações; perfeição mecânica; rapidez do cálculo; aptidão do cálculo mental e para a resolução de problemas. Segundo Gali (1929), a verificação desses diferentes aspectos poderia resultar num sistema de controle aritmético confuso e incompleto, facilmente confundido com a perfeição mecânica, a qual desconhecia a prática de ensino. E apenas o professor é que poderia ter alguma ideia sobre a implicação de séries graduadas na aprendizagem formal das operações. Tomando por exemplo a divisão, não era aceitável dizer que se o aluno soubesse dividir por três algarismos, então automaticamente saberia dividir por quatro. Para muitas crianças esse conhecimento não era espontâneo, mas deveria ser ensinado. Discordava o autor da ideia de que a perfeição mecânica consistia na aprendizagem de uma série de combinações necessárias para as operações aritméticas. Pelo contrário, ela consistia na precisão e na prática de operar, a ponto do processo se automatizar (GALI, 1929).

Do ponto de vista dos testes, Gali (1929) considerava incompreensível que nas séries iniciais fosse exigida, concomitantemente, perfeição mecânica e rapidez, duas situações consideradas antagônicas. Embora reconhecesse a importância dos estudos de Courtis, criticava-o por mensurar rapidez e perfeição concomitantemente. Já Burt, outro autor americano, tinha séries específicas para mensurar a rapidez e outras para a perfeição, entretanto não dedicava atenção especial a aquisição do mecanismo. É importante observar que Gali diferenciava rapidez de cálculo e rapidez de mecanismo. A primeira se referia a habilidade quase automática de se combinar números, enquanto que a segunda a habilidade de operar com eles.

A aritmética tinha uma peculiaridade: a existência de uma ordem interna lógica da própria disciplina onde um conteúdo dependia de conhecimentos prévios anteriores (GALI, 1929). E isso se comprovaria na aplicação de casos práticos, como por exemplo, nos problemas, onde a lógica das operações era inflexível. Cada problema exigia um grau de maturidade mental da mesma ordem que a aritmética apresentasse as operações. Raríssimos eram os casos em que uma criança resolveria problemas envolvendo a multiplicação, se não soubesse resolver a adição, pois a lógica da multiplicação se apresentaria em idade determinada e não se poderia alterar e exigir um grau de maturidade mental que a criança não possuía. Não negava que a criança pudesse aprender a 
multiplicação isoladamente, mas caso a idade não fosse adequada, esse conhecimento não seria suficiente para resolver problemas de multiplicação (GALI, 1929).

Gali (1929) se recusava a apresentar modelos de escalas sistematizadas e rígidas, se preocupava em orientar os leitores na elaboração de operações de modo a cumprir critérios da Escala de Operações ( 3 anos e meio até 13 anos de idade) e da Escala de problemas (5 anos e meio até 13 anos de idade). Tratava-se de escalas dividas em faixas etárias e juntamente com a habilidade aritmética esperada. Por exemplo, na escala de operações, dos 42 aos 78 meses de idade, era esperado que a criança somasse e subtraísse fazendo uso dos algarismos até a casa das dezenas. Para exemplificar, Gali (1929) apresentava modelos de operações para compor os testes, conforme figura 2.

Figura 2 - Modelo típicos para as operações

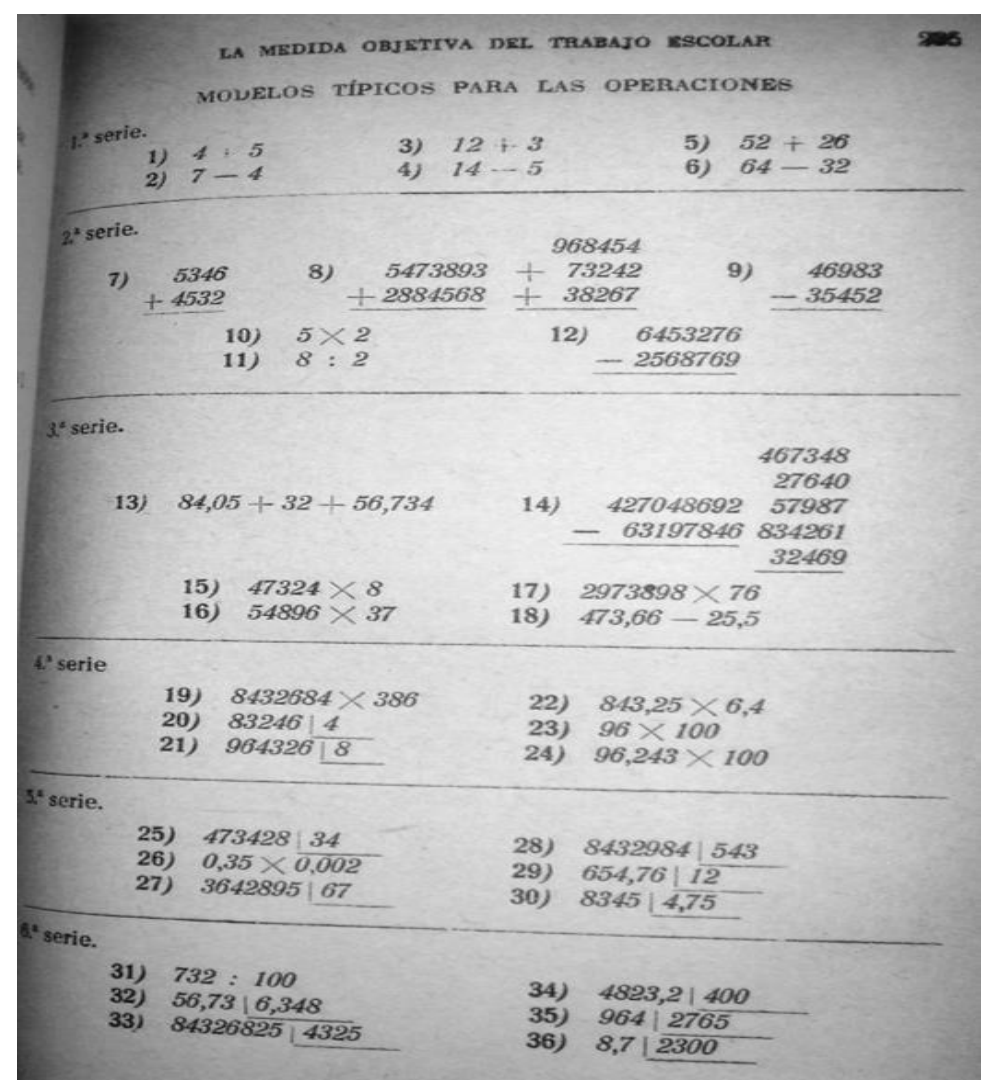

Fonte: Gali, 1929, p. 235.

Essa escala serviria de orientação para a construção dos testes para medir as capacidades operatórias dos alunos da escola primária. Entretanto, os testes não deveriam ser impressos em folhas especiais. Eles deveriam ser praticados como atividades do dia a dia escolar, como um trabalho de classe, no mesmo papel que estava habituado a fazer as atividades em sala.

Em relação à correção dos testes, diferentemente de outros autores que consideravam uma operação correta apenas se o resultado estivesse certo, Gali (1929) dava preferência ao mecanismo, o que justificava a tolerância aos erros de cálculo. Segue exemplo da operação de adição (Figura 3). 
Figura 3 - Exemplo da operação de adição

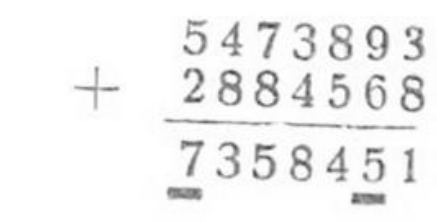

Fonte: Gali, 1929, p. 238.

Gali (1929, p. 238) considerava bem avaliada uma operação “cuando la mitad más uno de los casos específicos que la motivan han sido resultos, siempre que los casos que pudiéramos llamar neutros lo estén em la misma propoción”. Os estudos de Gali (1929) buscaram testar os conhecimentos dos alunos sem que eles notassem que estavam sendo avaliados. Tais estudos revelam esforços para adaptar os conteúdos escolares ao desenvolvimento psicológico da criança, mesmo no caso de disciplinas que eram consideradas possuidoras de uma lógica interna mais rígida, como era considerada a aritmética.

\section{Considerações Finais}

$\mathrm{Na}$ introdução desse artigo afirmamos que o objetivo do trabalho consistia em analisar as representações sobre a mensuração de habilidades aritméticas para a escola primária, postas na elaboração de um número específico da revista Escola Nova.

Não por acaso, Lourenço Filho se apropriou dos estudos de Gali e de Pressey e Pressey. Defensor das ideias advindas da psicologia de base estatística, o educador brasileiro acreditava que os testes influenciariam na organização das classes, no diagnóstico de aptidões, na organização dos programas e horários. Essas ferramentas psicológicas trariam uma nova dinâmica de ensino. Ao invés de se estabelecer o que as crianças deveriam aprender o foco recairia sobre aquilo que as crianças poderiam aprender, de acordo com o desenvolvimento psicológico. Essa perspectiva constituiu uma guinada fundamental a orientar as novas práticas pedagógicas.

Lourenço Filho também divulgou ao professorado um modo científico de tratar as questões escolares. Tal divulgação ganhou conteúdo a partir das suas apropriações de referências vindas do exterior. A publicação da revista Escola Nova funcionou como elemento de estratégia a fim de falar mais de perto aos docentes, buscando convencê-los de que sua prática pedagógica poderia ter mais eficiência contando com as descobertas da psicologia experimental de base estatística.

No texto de Gali (1931) fica evidente a preocupação de introduzir o professorado na elaboração dos testes, cujo objetivo principal não era uma mudança nas práticas pedagógicas, mas a adaptação do programa escolar ao desenvolvimento psicológico das crianças. Diferentemente de Gali, a proposta de Pressey, S. e Pressey, L. era de transformar o ambiente escolar num laboratório para diagnosticar os problemas de aprendizagens dos alunos, detectados pela ineficiência dos 
ensinos, resolvendo a questão a partir de métodos adequados. No processo de circulação dessas duas representações tão distintas, nota-se um movimento de busca da autonomia da pedagogia à psicologia no trato das questões escolares relativamente ao uso dos testes. Essa parece ser a marca distintiva maior entre as duas obras analisadas neste texto.

A construção das representações que hoje nos chegam sob a forma de classes fortes, fracas, questões de avaliação fáceis, médias e difíceis, alunos fracos, fortes em matemática, remonta à penetração da psicologia experimental de base estatística. Mais especificamente, teve nas ações de Lourenço Filho, por meio do periódico Escola Nova, uma poderosa estratégia de convencimento do professorado.

Por fim, note-se que o acento para a melhoria das questões escolares, mesmo considerando-se a entrada do sujeito psicológico - o aluno - recai sobre a eficiência do ensino. Não estão presentes, ainda, como foco principal, as questões relativas à aprendizagem, à aprendizagem matemática, à construção de modelos de aprendizagem dos primeiros passos na matemática. Há que se ter um ensino que respeite a psicologia do aluno, e isso implicaria numa forma de garantir uma maior eficiência do trabalho docente, sobretudo, com a aritmética escolar.

\section{Referências}

CHARTIER, R. A História Cultural: entre práticas e representações. Lisboa: Difel; Rio de Janeiro: Bertrand Brasil S.A., 2002.

DE CERTEAU. M. A invenção do Cotidiano: 1. Artes do fazer. 18. ed. Tradução de Ephraim Ferreira Alves. Petrópolis, RJ: Vozes, 2012.

CHAMON, GALI, A. La medida objectiva Del trabajo escolar. Madrid: 1929

GALI, A. Conceito de medida do trabalho escolar. In: Introdução aos estudos dos Tests. Escola Nova, São Paulo, vol. II, n ${ }^{\text {os }} .3$ e 4, p. 260 - 303, mar/abr. 1931.

LOURENÇO FILHO, M. B. Introdução ao estudo da escola nova: bases, sistemas e diretrizes da pedagogia contemporânea. São Paulo: Edições Melhoramentos, 1930.

Os Tests. In: Introdução aos estudos dos Tests. Escola Nova, São Paulo, vol. II, $\mathrm{n}^{\text {os }} .3$ e 4, p. 253 - 259, mar./abr. 1931.

MELLO, M. C. de O. A Alfabetização na imprensa periódica educacional paulista (1927 1943). Tese (Doutorado em Educação). UNESP de Marília, 2007.

PRESSEY, S.; PRESSEY, L. C. Introduction to the use of standard tests: brief manual in the use of both ability an achievement in school subjects. New York: World Book Company, 1922. Disponível em: https://ia600401.us.archive.org/15/items/introductiontous00pres/introductiontous00pres.pdf. Acesso em 17 out. 2014. 